\title{
Electrical Resistivity Tomography applied in springs area in Cuiabá City, Mato Grosso State, Brazil: preliminary result
}

Niara Rodrigues Albino Barroso ${ }^{1} \quad$ (nrodrigues909@gmail.com); Rejane Suellen da Silva Duarte ${ }^{2}$ (geologa.rejaneduarte@gmail.com); Cristiane Dias de Novaes² (cristianediasdenovaes@hotmail.com), Sergio Junior da Silva Fachin³ (fachinjr@ufmt.br);

\author{
${ }^{1}$ Graduate student of the Faculdade de Geociências, FAGEO/UFMT \\ ${ }^{2}$ Geologist of the AGUA PARA O FUTURO Project \\ ${ }^{3}$ Professor of the Faculdade de Geociências, FAGEO/UFMT
}

Copyright 2019, SBGf - Sociedade Brasileira de Geofísica

This paper was prepared for presentation during the 16th International Congress of the Brazilian Geophysical Society held in Rio de Janeiro, Brazil, 19-22 August 2019.

Contents of this paper were reviewed by the Technical Committee of the 16th International Congress of the Brazilian Geophysical Society and do not necessarily represent any position of the SBGf, its officers or members. Electronic reproduction or storage of any part of this paper for commercial purposes without the written consent of the Brazilian Geophysical Society is prohibited.

\section{ABSTRACT}

In this work we present the preliminary result with Electrical Resistivity Tomography (ERT) method, executed in Cuiabá City, Mato Grosso State, Brazil. The ERT result show a low resistivity anomaly, which we believe to be a fracture zone that form spring areas in ground.

\section{INTRODUCTION}

The WATER FOR THE FUTURE Project is an initiative of the Public Ministry of the State of Mato Grosso (MPMT), together with the Federal University of Mato Grosso (UFMT). The project seeks to guarantee water security and the supply of drinking water by identifying and characterizing springs areas in the city of Cuiabá, Mato Grosso State, Brazil. Springs areas are defined as an environmental system marked by a geomorphological feature or geological structure in which the exfiltration of the water occurs in a temporary or perennial way, forming drainage channels downstream. The removal of the natural vegetation, the waterproofing of the soil and the channeling of the drainage, causes the decharacterization, the reduction of the flow and, finally, the disappearance of spring water areas. The objective this study is show geophysical preliminary result (Electrical Resistivity Tomography) in springs area, show in Figure 1.

Geophysical methods can play an important role in the acquisition of such knowledge (Dahlin, 1996). The geophysics near-surface methods and techniques are sensitive to physical properties of the substrate and hence act as proxies geological, hydrological and biogeochemical parameters (McLachlan et. al., 2017).

Resistivity values are highly affected by several variables, including the presence of water or moisture, and the amount and distribution of pore space in the material (Rucker and Glaser, 2015).

The Electrical Resistivity Tomography (ERT) is used to determine subsurface electrical resistivity by injecting electrical currents into the ground one pair stainless steel electrode and to measure electric potential in other stainless steel electrode pair. ERT multi-electrode survey systems are capable to acquired stronger resistivity data sets.

\section{RESULTS}

For this work we used the multi-electrode resistivity equipment Syscal PRO apparatus from Iris Instruments with a total of 48 stainless steel electrodes. Acquisition protocol had in Electre Pro version II (free version), by Iris Instruments. The electrode array selected was dipoledipole and spacing between the electrodes was 03 meters. Resistivity line was 188 meters. Data survey had a very low $(<5 \mathrm{k} \Omega$ ) contact impedance between the electrodes and the ground.

The data set were processed and modeled with the RES2DINV, version 4.05 (Geotomo Software, 2017), which uses a finite-element grid for the forward analysis. Topography was include in the data inversion. ERT data survey with 2140 points measured. The low misfit error $(5.4 \%)$ at the five iterations in the inversion of the apparent resistivity data.

The Figure 2 show resistivity 2-D. Note that in this preliminary result indicate a significant resistivity anomaly between 90 and $100 \mathrm{~m}$. The low resistivity anomaly $(<40$ $\Omega \mathrm{m})$ starts at the surface and extends as deep 30 meters.

\section{CONCLUSION}

In summary, the spring area ERT survey indicate significant low resistivity anomaly in depth. This low resistivity anomaly is probably generated combination the local geological conditions: groundwater flow in the fractures zones that form spring areas in surface. The existence of shallow unconfined water in situ confirm the probably fracture zone. 


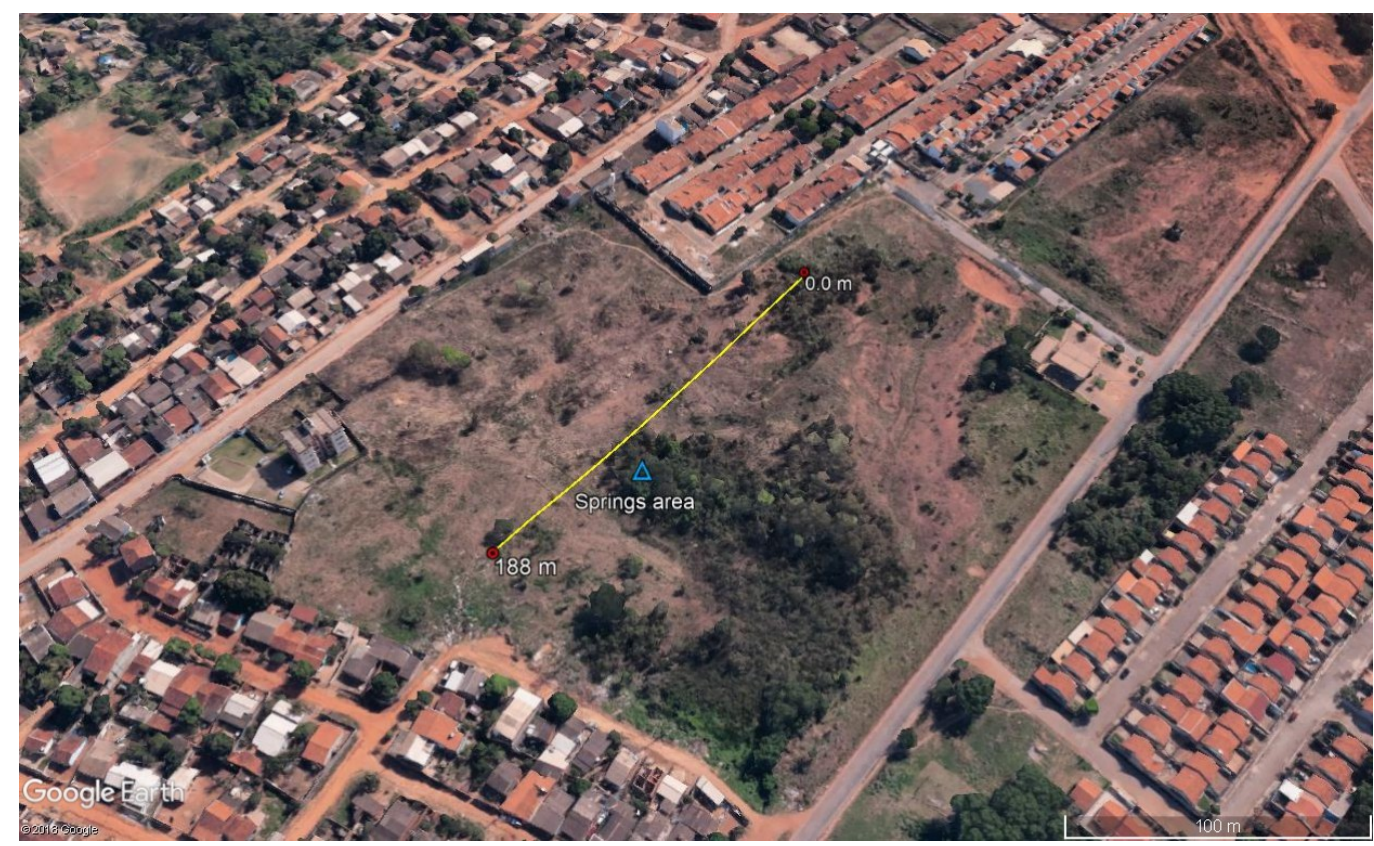

Figure 1. Location of the spings area in urban area of Cuiabá City, Mato Grosso State Brazil: The yellow line represents the ERT survey, red circles represents the initial and final profile and blue triangle is springs local area.

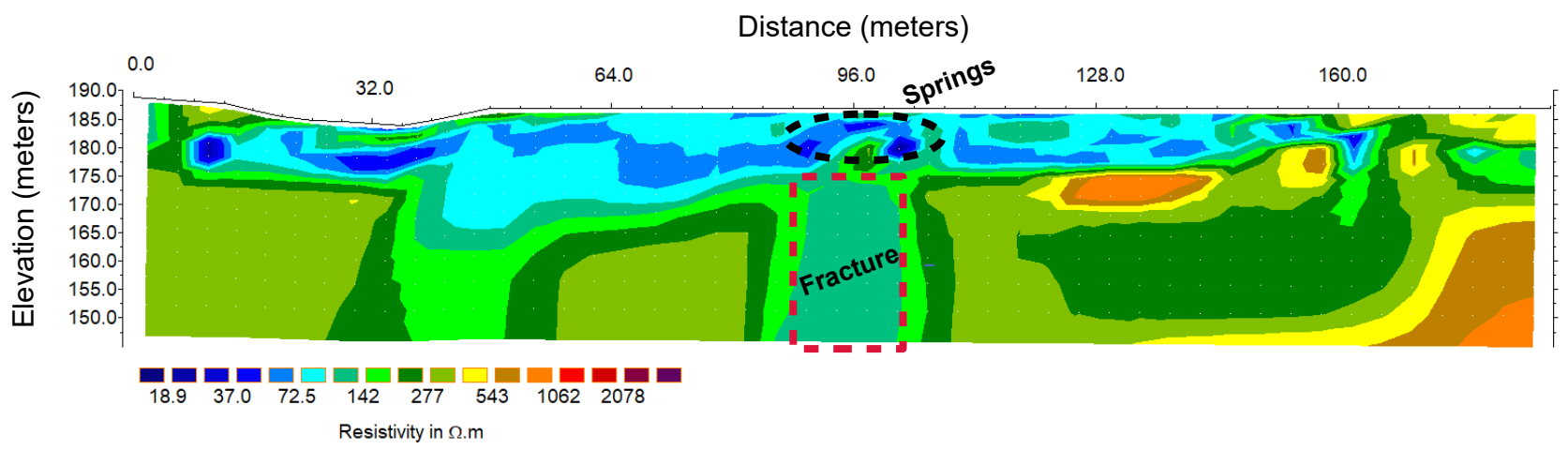

Figure 2. Resistivity 2-D model with topography in springs area: Dipole-dipole electrode array, 04 meters electrode spacing, 188 meters long profile and five iterations and $5.4 \%$ misfit error.

\section{Acknowledgments}

This work was supported by AGUA PARA O FUTURO Project and Federal University of Mato Grosso (UFMT). We also thanks the Public Ministry of the State of Mato Grosso (MPMT) and FUNASA-MT for geophysical software and equipment.

\section{References}

DAHLIN, T. 2D resistivity surveying for environmental and engineering applications. First Break, Issue 7, Volume 14. https://doi.org/10.3997/1365-2397.1996014. 1996.
GEOTOMO SOFTWARE. User Manual RES2DINVx64 version 4.05: Rapid 2-D Resistivity \& IP inversion using the least-squares methods, 136 pages. 2017.

MCLACHLAN, P. J.; CHAMBERS, J. E.; UHLEMANN, S. S.; BINLEY, A. Geophysical characterisation of the groundwater-surface water interface. Advances in Water Resources, Volume 109, pages 302-319, ISSN 03091708, https://doi.org/10.1016/j.advwatres.2017.09.016. 2017.

RUCKER, D. F. and GLASER, D. R. Standard, random and optimum array conversions from two-pole resistance data. J. Environ. Eng. Geophys. 20 (3), 207-217. 2015. 
Sixteenth International Congress of the Brazilian Geophysical Society 